\title{
Development of an Eco-Friendly Reversed-Phase HPLC Method for the Simultaneous Determination of Three Emerging Contaminants in Water Samples
}

\author{
Nardine Safwat ", Miriam F. Ayad, Maha F. Abdel-Ghany \\ Pharmaceutical Analytical Chemistry Department, Faculty of Pharmacy, Ain Shams University, Cairo 11566, Egypt
}

\begin{abstract}
Nowadays, applying green analytical principles in analytical chemistry without affecting the figures of merit is challenging to perform. One of the most important factors that contribute to greening an analytical method is to avoid the use of hazardous solvents and the tendency to use what is so-called green solvents since most of the chromatographic methods depend on using hazardous solvents. In this work, a green reversed-phase HPLC/DAD method has been developed for the simultaneous detection of three emerging contaminants in environmental water samples that have a highly negative impact on the environment. The simultaneous determination of the three emerging contaminants including diclofenac, carbamazepine, and triclosan, carried out in two different types of water samples, was achieved on Atlantis T3 RP $\mathrm{C}_{18}$ column $(250 \mathrm{~mm} \times 4.6 \mathrm{~mm}$ i.d $\times 5 \mu \mathrm{m})$ using a green isocratic mobile phase; ethanol: water $(85: 15, \mathrm{v} / \mathrm{v})$ pumped at a flow rate $0.8 \mathrm{mLmin}^{-1}$. The linear concentration ranges obtained were 20 1000 ng.mL ${ }^{-1}$, 60-1000 ng. $\mathrm{mL}^{-1}$ and 60-2000 ng. $\mathrm{mL}^{-1}$ for diclofenac, carbamazepine, and triclosan respectively. The limit of detection and limit of quantitation were $(3.66,11.09),(7.51,22.75)$ and $(7.22$, 21.88) ng. $\mathrm{mL}^{-1}$ for diclofenac, carbamazepine, and triclosan, respectively. The method was validated by the International Conference on Harmonization guidelines. Finally, two evaluation tools known as Analytical Eco-scale and Green analytical procedure index were adopted to evaluate the greenness of the proposed method. A comparison between the obtained results and the published results was carried out and no significant differences were found.
\end{abstract}

Keywords: water analysis; environmental analysis; emerging contaminant; green solvents; green analytical methodology.

*Correspondence | Nardine Safwat; Pharmaceutical Analytical Chemistry Department, Faculty of Pharmacy, Ain Shams University, Cairo 11566, Egypt. Email: nardine.safwat2@pharma.asu.edu.eg

Citation | Safwat N, Ayad M F, Abdel-Ghany M F, 2020. Development of an eco-friendly reversed-phase HPLC method for the simultaneous determination of three emerging contaminants in water samples. Arch Pharm Sci ASU 4(1): 79-91

DOI: $10.21608 /$ APS.2020.2001.1025

Print ISSN: 2356-8380. Online ISSN: 2356-8399.

Received 04 February 2020. Accepted 23 March 2020.

Copyright: ${ }^{\circledR} 2020$ Safwat et al. This is an open-access article licensed under a Creative Commons Attribution 4.0 International License (CC BY 4.0), which permits unrestricted use, distribution, and reproduction in any medium, provided the original author(s) and source are credited.

Published by: Ain Shams University, Faculty of Pharmacy

\section{INTRODUCTION}

Pharmaceuticals and personal care products' emergence in the environment has become an important issue in the past years. The problem started in 1970 when several toxicological reports demonstrated the impact of these emerging contaminants on aquatic organisms $[\mathbf{1}, \mathbf{2}]$. These emerging contaminants differ from classical pollutants since they are continuously released to the environment via different sources including excretion of pharmaceuticals not completely metabolized by the body or their 
pharmacologically active metabolites or their incomplete elimination or transformation during sewage water treatment or due to inappropriate citizens', hospitals' or industrial discharges and finally reaching surface water [3, 4] Although, these emerging contaminants may occur at trace levels in the environment in the range of $\mu \mathrm{g} . \mathrm{L}^{-1}$ to ng. $\mathrm{L}^{-1}$, they may pose toxic cumulative and synergistic effects on human and other living organisms [5].

Several toxicological reports have demonstrated the possible diclofenac induced renal failure and liver damage effects [6]. Moreover, triclosan, which is commonly employed in personal care products as an antimicrobial agent, is highly toxic since it doesn't only affect the thyroid hormone homeostasis and the aquatic organisms but it may be converted to more toxic degradation products which are known to be even more toxic endocrine disruptors such as dioxins and chlorine phenolic compounds besides the development of bacterial resistance [7]. Carbamazepine was also considered as one of the most commonly detected pharmaceuticals in drinking water and was reported to be highly toxic when tested on various embryonic cells $[\mathbf{8}, \mathbf{9}]$.

From this point of view, we have chosen the previously mentioned compounds to be the subject of our study; Diclofenac (DCF), which is chemically known as Sodium [o-(2,6dichloranilino) phenyl] acetate (Fig. 1a), a common anti-inflammatory drug, also used as an analgesic drug in some diseases, Carbamazepine (CBZ), which is chemically known as $5 \mathrm{H}$ dibenzo [b,f ]azepine-5-carboxamide (Fig. 1b), commonly used in partial epilepsy, trigeminal neuralgia and as an adjunct to neuroleptic therapy in psychosis and Triclosan (TCS), that is chemically known as 5-chloro-2-[2,4-dichlorophenoxy]-phenol (Fig. 1c), a broad-spectrum antimicrobial agent used in personal care products.<smiles>COC(=O)Cc1ccccc1Nc1c(Cl)cccc1Cl</smiles>

(a)

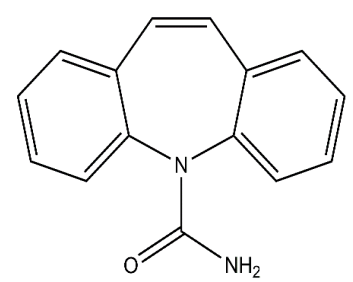

(b)

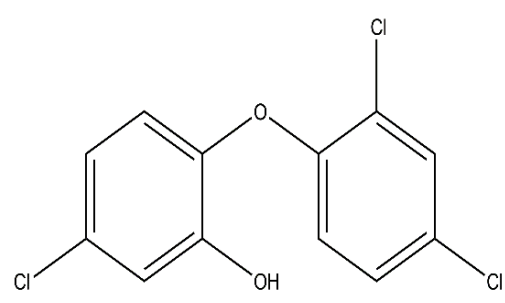

(c)

Fig. 1. Chemical structures of diclofenac (a), carbamazepine (b) and triclosan (c)

Most of the methods employed in the analysis of these emerging contaminants include liquid chromatography-tandem mass spectrometry and gas chromatography-tandem mass spectrometry [10-16]. Although the latter methods have high accuracy and sensitivity, they are highly 
expensive and require the utilization of huge amounts of toxic chemicals and solvents.

This work aimed to develop green, sensitive, simple and economic methods for the analysis of these compounds in different water samples. It was also taken into consideration the need to design a greener methodology by eliminating the use of toxic chemicals and solvents and be ecofriendly.

\section{MATERIALS AND METHODS}

\subsection{Chemicals and materials}

HPLC grade chemicals were utilized throughout this work: water, methanol, and ethanol (Fisher, Cornell Lab, Cairo, Egypt) were used for all the experiments. Carbamazepine pure sample, kindly supplied by Novartis pharmaceutical company, was found to be 99.83\% pure, diclofenac pure sample, kindly supplied by Pharaonic pharmaceutical company, was found to be $99.95 \%$, and triclosan pure sample, purchased from Sigma- Aldrich (Germany), was found to be $100.24 \%$ according to the reported reference methods [17-19].

\subsection{Instrumentation}

Waters Alliance e2695 HPLC binary pump (Waters Technology, Milford, MA) equipped photodiode array detector (model 2998).

Atlantis T3 RP $\mathrm{C}_{18}$ column $(250 \mathrm{~mm} \times 4.6 \mathrm{~mm}$ i.d $\times 5 \mu \mathrm{m})$.

$0.22 \mu \mathrm{m}$ disposable membrane filters (Millipore corp., Milford, MA, United States).

Sonicator (Crest ultrasonic, scotch road. Mercer, country airport, Trenton, NJ 08628).

Solid Phase Extraction: 12 Port Vacuum Extraction Manifold Assy (Phenomenex) with Vacuum Pump, Beco, Germany.

Vortex mixer (F20230176 ZX3, Alfa medical Westbury, China).

\subsection{Preparation of standard solutions}

Preparation of stock solutions of concentration $\left(100 \mu \mathrm{gmL}^{-1}\right)$ of each of $\mathrm{DCF}$, CBZ, and TCS was separately carried out by dissolving $0.01 \mathrm{~g}$ of each drug in a mixture of ethanol: water $(85: 15, \mathrm{v} / \mathrm{v})$ in a $100 \mathrm{~mL}$ volumetric flask. All stock solutions were kept in the refrigerator at $4{ }^{\circ} \mathrm{C}$ for further use and were stable for a month.

\subsection{Chromatographic conditions}

The mobile phase was filtered through a 0.2 $\mu \mathrm{m}$ membrane filter and degassed in an ultrasonic bath for $30 \mathrm{~min}$ before its use. The temperature of the column was adjusted at $25{ }^{\circ} \mathrm{C}$. The injection volume was $40 \mu \mathrm{L}$. The mobile phase consisting of ethanol: water $(85: 15, \mathrm{v} / \mathrm{v})$ was used at a flow rate of $0.8 \mathrm{~mL} \mathrm{~min}^{-1}$ with UV detection at $283 \mathrm{~nm}$ with a short run time of 6 $\min$.

\subsection{Environmental samples}

Two different types of water samples were carefully collected in amber glass bottles, prerinsed with ultra-pure water, obtained from a water treatment plant to avoid any photodegradation and were filled with no headspace remaining. The first batch was representative untreated drinking water samples obtained from the treatment plant which receives water from pipes placed $100 \mathrm{Km}$ apart in the Nile River. The second batch was treated with drinking water samples obtained just after the treatment was done and before being distributed to other areas. The samples were kept at $4{ }^{\circ} \mathrm{C}$ during transportation to the laboratory. Upon receiving, the samples were vacuum filtered with $0.45 \mu \mathrm{m}$ nylon membrane filters and stored in the refrigerator at $4{ }^{\circ} \mathrm{C}$ until solid-phase extraction (SPE) which was carried out within $24 \mathrm{~h}$ to avoid any microbial degradation and to avoid the use of any preservative to be eco-friendly. 


\subsection{Procedures}

\subsubsection{Construction of calibration curves}

Aliquots of the previously prepared standard solutions of DCF, CBZ and TCS were used to prepare three separate serial dilutions in $10 \mathrm{~mL}$ volumetric flasks and were diluted to the final volume with the mobile phase and mixed well, covering the concentration ranges (20-1000 ng $\left.\mathrm{mL}^{-1}\right),\left(60-1000 \mathrm{ng} \mathrm{mL}^{-1}\right)$ and $\left(60-2000 \mathrm{ng} \mathrm{mL}^{-1}\right)$ respectively. The peak areas were plotted against their corresponding concentrations and the regression equations were obtained.

\subsubsection{Analysis of laboratory prepared mixtures}

Different aliquots of stock standard solutions of DCF, CBZ, and TCS were accurately transferred to a series of $10 \mathrm{~mL}$-volumetric flasks within the linearity ranges of the related compounds in different ratios.

\subsubsection{Application of the proposed method for the determination of DCF, CBZ, and TCS in drinking water samples before and after treatment}

The samples were first extracted using solid phase and then analyzed to determine whether the compounds being studied are present or not without the addition of pure stock solutions. After that, standard addition and spiking methods were adopted using three different concentrations of each drug to ensure the proposed method validity.

The SPE was carried out using SPE Strata $C_{18}$ cartridges (1 mL, $200 \mathrm{mg})$ from Phenomenex (United States). The cartridges were preconditioned with $5 \mathrm{~mL}$ methanol and $3 \mathrm{~mL}$ of ultrapure water (of HPLC grade). For treated and untreated drinking water samples, the $\mathrm{pH}$ of the samples and ultrapure water used for preconditioning was adjusted to $4.1(\mathrm{HCl})$. The sample is then loaded at a flow rate not greater than 15 inches of mercury and the cartridge was dried by applying vacuum to remove excess water. The retained analytes were eluted using the proposed mobile phase, ethanol: water $(85: 15, \mathrm{v} / \mathrm{v})$ for HPLC analysis. All the analysis was carried out in triplicate.

\section{RESULTS AND DISCUSSION}

HPLC/DAD technique is widely used for its high sensitivity, specificity, and reproducibility and to achieve the optimum chromatographic separation without affecting the greenness of the proposed method, different mobile phase compositions and ratios were tested to provide the best separation with optimum selectivity and sensitivity in short run time. The use of a benign solvent instead of toxic and hazardous solvents and shortening the run time was essential to act by the green analytical chemistry principles [20]. It's worth mentioning that from our literature survey all the chromatographic methods used either methanol or acetonitrile as organic modifiers in the mobile phase. According to the environmental protection agency, both methanol and acetonitrile are classified as hazardous solvents owing to their inherent toxicity [21].

\subsection{Method development and Optimization}

\subsubsection{Effect of the mobile phase composition on peak shape and separation in HPLC}

Different organic modifiers were tested including methanol, ethanol, and acetonitrile. Moreover, different ratios of ethanol: water was studied including (95:5, 90:10, 85:15, 80:20, $75: 25,70: 30)$. The best results were obtained using methanol: water $(85: 15, \mathrm{v} / \mathrm{v})$ as the mobile phase for separation. Therefore, the use of ethanol was a benign alternative to both methanol and acetonitrile according to Sadek [22-24]. The three compounds were well separated in a very short time of about $6 \mathrm{~min}$, which was a great contribution to achieving a green method (Fig. 2). 


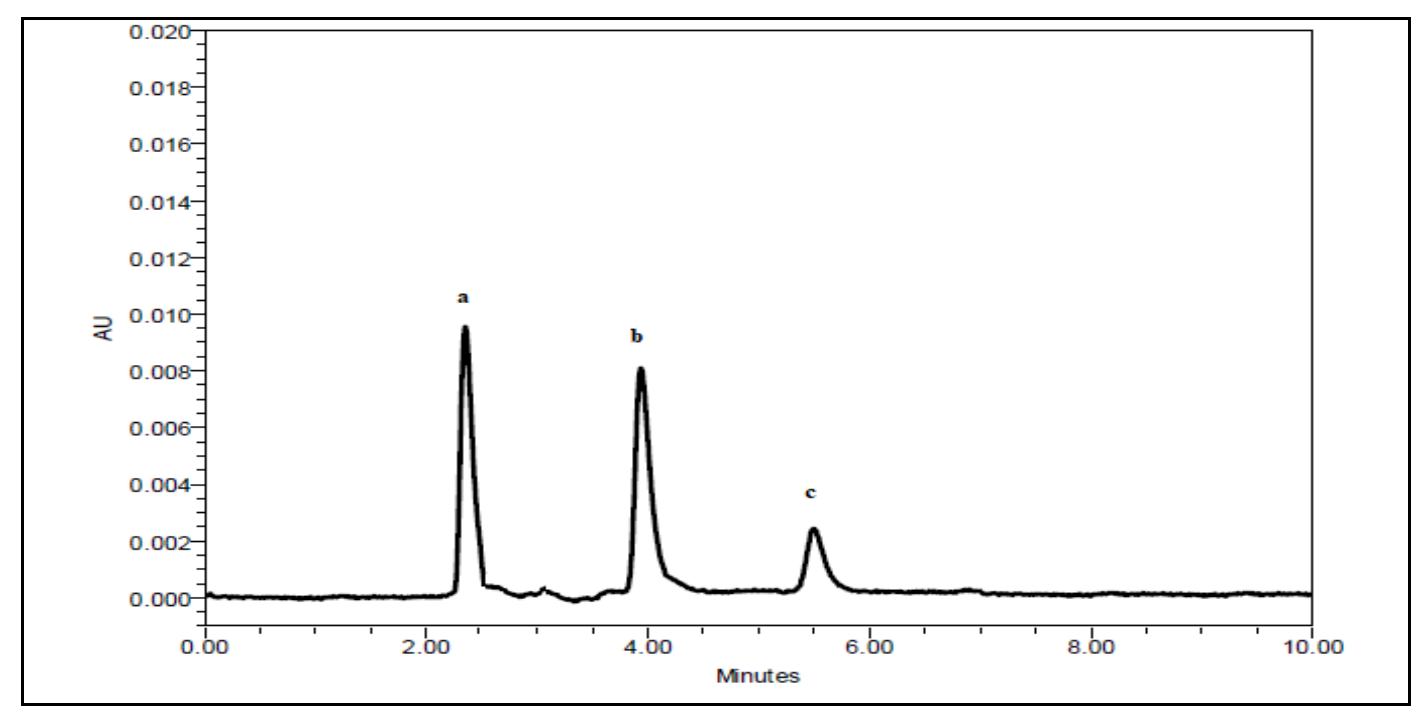

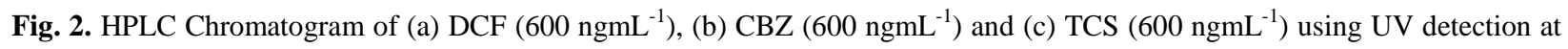
$283 \mathrm{~nm}$

\subsubsection{Effect of the flow rate on peak shape and separation in HPLC}

Different flow rates $\left(0.8,0.9,1 \mathrm{~mL} \min ^{-1}\right)$ were tested, $0.8 \mathrm{~mL} \min ^{-1}$ was found to be optimum for the separation.

\subsubsection{System suitability tests}

System suitability tests are necessary for any liquid chromatographic method to optimize the conditions to obtain the best separation. The parameters include some theoretical plates $(\mathrm{N})$, tailing of chromatographic peak ( $\mathrm{T})$, capacity factor $(\mathrm{K})$, a resolution between peaks (Rs), height equivalent to a theoretical plate (HETP) and selectivity factor $(\propto)$ (Table 1).

\subsection{Method Validation}

Validation of the proposed method was carried out by the ICH guidelines [25].

\subsubsection{Linearity and range}

DCF, CBZ, and TCS were measured according to the procedure under (3.1.) and a linear relation was obtained between the peak area values and their corresponding concentrations and the characteristic parameters of the regression equations were then computed
(Table 2).

\subsubsection{Accuracy}

For the proposed method, accuracy was measured by computing the \%recovery of five different concentrations of each compound using the regression equations. The proposed method was found to be accurate based on the calculated mean of the recovery and standard deviation (Table 2).

\subsubsection{Precision}

\subsubsection{Repeatability (Intraday precision)}

for the proposed method, three different concentrations of each compound were measured three times on the same day and the RSD \% was calculated.

\subsubsection{Intermediate Precision (Interday Precision)}

The same concentrations used for intraday precision were measured on three successive days. RSD \% was calculated.

Based on the low RSD \% acceptable values, the proposed method shows good precision. The $\%$ RSD for the three concentrations of each 
compound was found to be less than $2 \%$ in the three concentrations (Table 2).

\subsubsection{LOD and LOQ}

LOQ values were determined by establishing the measurable concentrations below which the calibration graph is nonlinear $(\mathrm{LOQ}=10 \times$ standard deviation of the response /slope). LOD values were determined by evaluating the lowest analyte concentrations that can be readily detected ( $L O D=3.3 \times$ standard deviation of the response /slope) (Table 2).

\subsubsection{Robustness}

The proposed HPLC method is robust and unaffected by the small changes which were carried out either the change in wavelength $( \pm 2$ $\mathrm{nm})$ or the change in the mobile phase composition $( \pm 5 \%)$. This was concluded according to \%RSD which was found to be less than 2\% (Table 2).

\subsection{Assay of laboratory prepared mixtures}

Five different laboratory mixtures containing the studied compounds were prepared with different concentrations and ratios and the concentrations were computed using the linear regression equations with good recoveries (Table 3).

Table 1. System suitability parameters of the proposed HPLC/DAD method

\begin{tabular}{|c|c|c|c|c|}
\hline Parameter & DCF & CBZ & TCS & Reference value [30] \\
\hline Tailing factor $(\mathbf{T})$ & 1 & 1.5 & 1.25 & $\mathrm{~T} \leq 2$ \\
\hline Capacity factor (K') & 2.235 & 4.415 & 6.561 & $K^{\prime}>2$ \\
\hline Selectivity factor $^{a}(\propto)$ & 1.975 & 1.486 & & $\propto>1$ \\
\hline Resolution $^{b}\left(\mathbf{R}_{\mathrm{s}}\right)$ & 6.3 & 5.2 & & $\mathrm{R}_{\mathrm{s}}>2$ \\
\hline $\begin{array}{l}\text { Number of theoretical } \\
\text { plates }^{c}(N)\end{array}$ & 2212.76 & 2755.55 & 5371.91 & $N>2000$ \\
\hline $\begin{array}{l}\text { Height equivalent to } \\
\text { theoretical plate } \\
\text { (HETP) }\end{array}$ & 0.11 & 0.091 & 0.047 & $\begin{array}{l}\text { The smaller the value, } \\
\text { the higher the column } \\
\text { efficiency }\end{array}$ \\
\hline
\end{tabular}

\footnotetext{
${ }^{a}$ Selectivity was calculated according to the capacity factors of two successive peaks

${ }^{b}$ Resolution was calculated according to the retention times of two successive peaks

${ }^{c}$ Measure column efficiency
} 
Table 2. Results of assay validation of the proposed method for the determination of emerging contaminants in water samples

\begin{tabular}{|c|c|c|c|}
\hline Parameter & $\overline{D C F}$ & $\overline{C B Z}$ & TCS \\
\hline Working $\lambda \mathbf{n m}$ & 283 & 283 & 283 \\
\hline Retention time & 2.59 & 4.00 & 5.62 \\
\hline Range (ng.mL $L^{-1}$ ) & $20-1000$ & $60-1000$ & $60-2000$ \\
\hline slope & 119933 & 128127 & 36660 \\
\hline Intercept & 7574.7 & 1109.7 & 434.16 \\
\hline $\mathbf{r}$ & 0.9999 & 0.9999 & 0.9998 \\
\hline LOD (ng.mL $\left.L^{-1}\right)$ & 3.66 & 7.51 & 7.22 \\
\hline LOQ (ng.mL $\left.L^{-1}\right)$ & 11.09 & 22.75 & 21.88 \\
\hline $\begin{array}{l}\text { Accuracy } \\
(\text { Mean } \pm \text { SD })\end{array}$ & $100.42 \pm 1.381$ & $99.56 \pm 0.733$ & $99.69 \pm 0.919$ \\
\hline Intraday RSD \% & & & \\
\hline Interday RSD\% & $\begin{array}{l}1.817 \\
1.766\end{array}$ & $\begin{array}{l}1.673 \\
1.834\end{array}$ & $\begin{array}{l}1.857 \\
1.644\end{array}$ \\
\hline $\begin{array}{l}\text { Wavelength } \\
(283 \pm 2 \mathrm{~nm}) \\
\% \mathrm{RSD}\end{array}$ & $0.099-0.320$ & $0.226-0.339$ & $0.121-0.325$ \\
\hline Robustness & & & \\
\hline $\begin{array}{l}\text { Mobile phase } \\
\text { composition } \\
( \pm 5 \%), \% \text { RSD }\end{array}$ & $1.350-1.462$ & $0.564-0.648$ & $0.169-0.737$ \\
\hline
\end{tabular}

Table 3. Assay results for the simultaneous determination of the studied compounds in synthetic lab prepared mixtures using the proposed methods

\begin{tabular}{cccc}
\hline \multirow{2}{*}{$\begin{array}{c}\text { Ratio of mixture components } \\
\text { (DCF: CBZ: TCS) }\end{array}$} & DCF & CBZ Recovery \\
\cline { 2 - 4 } & 98.46 & 100.39 & TCS \\
\hline $\mathbf{1 : 1 : 1}$ & 98.78 & 100.01 & 98.82 \\
$\mathbf{1 : 1 : 2}$ & 102.61 & 98.93 & 98.07 \\
$\mathbf{1 : 2 : 1}$ & 99.27 & 100.98 & 100.62 \\
$\mathbf{2 : 1 : 1}$ & 101.73 & 101.08 & 100.12 \\
$\mathbf{1 : 2 : 3}$ & $100.17 \pm 1.873$ & $100.28 \pm 0.870$ & 99.55 \\
Mean \pm SD & & $99.44 \pm 1.018$ \\
\hline
\end{tabular}


Table 4. Determination of DCF, CBZ and TCS in untreated and treated water samples using the proposed HPLC/DAD method

\begin{tabular}{|c|c|c|c|c|c|c|c|c|c|}
\hline \multirow[t]{2}{*}{ Sample } & \multicolumn{3}{|c|}{$\overline{D C F}$} & \multicolumn{3}{|c|}{$\overline{C B Z}$} & \multicolumn{3}{|c|}{ TCS } \\
\hline & $\begin{array}{c}\text { Pure added } \\
\text { (ng. } \\
\left.\text { mL }^{-1}\right)\end{array}$ & $\begin{array}{c}\begin{array}{c}\text { Pure } \\
\text { found }^{*} \\
(\mathbf{n g} . \\
\left.\mathbf{m L}^{-1}\right)\end{array} \\
\end{array}$ & Rec. \% & $\begin{array}{c}\text { Pure added } \\
\text { (ng. } \\
\text { mL }^{-1} \text { ) }\end{array}$ & $\begin{array}{c}\text { Pure } \\
\text { found } \\
(\mathbf{n g} . \\
\left.\mathbf{m L}^{-1}\right)\end{array}$ & Rec. \% & $\begin{array}{c}\text { Pure added } \\
\text { (ng. } \\
\text { mL }^{-1} \text { ) }\end{array}$ & $\begin{array}{c}\begin{array}{c}\text { Pure } \\
\text { found }\end{array} \\
(\mathbf{n g} . \\
\left.\text { mL }^{-1}\right)\end{array}$ & Rec. \% \\
\hline $\begin{array}{l}\text { Blank untreated } \\
\text { water }\end{array}$ & 0 & 55.34 & & 0 & $\mathrm{nf}^{* *}$ & & 0 & $\mathrm{nf}^{* *}$ & \\
\hline Spiked Sample 1 & 600 & 599.86 & 99.98 & 600 & 596.81 & 99.47 & 600 & 599.70 & 99.95 \\
\hline Spiked Sample 2 & 400 & 402.78 & 100.69 & 400 & 401.61 & 100.40 & 400 & 400.08 & 100.02 \\
\hline Spiked Sample 3 & 200 & 203.16 & 101.58 & 200 & 203.38 & 101.69 & 200 & 200.92 & 100.46 \\
\hline Mean \pm SD & & & $\begin{array}{c}100.75 \\
\pm \\
0.802\end{array}$ & & & $\begin{array}{c}100.52 \\
\pm \\
1.115\end{array}$ & & & $\begin{array}{c}100.14 \\
\pm \\
0.276\end{array}$ \\
\hline $\begin{array}{l}\text { Blank treated } \\
\text { water }\end{array}$ & 0 & 37.82 & & 0 & $\mathrm{nf}^{* *}$ & & 0 & $\mathrm{nf}^{* *}$ & \\
\hline Spiked Sample 1 & 600 & 595.91 & 99.32 & 600 & 598.74 & 99.79 & 600 & 604.52 & 100.75 \\
\hline Spiked Sample 2 & 500 & 493.08 & 98.62 & 500 & 501.95 & 100.39 & 500 & 495.36 & 99.07 \\
\hline Spiked Sample 3 & 400 & 404.28 & 101.07 & 400 & 399.06 & 99.77 & 400 & 397.21 & 99.30 \\
\hline Mean \pm SD & & & $\begin{array}{l}99.67 \pm \\
1.262\end{array}$ & & & $\begin{array}{c}99.98 \pm \\
0.352\end{array}$ & & & $\begin{array}{c}99.71 \pm \\
0.911\end{array}$ \\
\hline
\end{tabular}

Mean of three determinations.

${ }^{* *} n f=$ not found.

\subsubsection{Assay of the concentration of the studied emerging contaminants in various water samples}

The proposed method had been successfully applied for the determination of studied compounds in different water samples. DCF was detected in a concentration of (55.34 $\left.\mathrm{ng} \mathrm{mL}^{-1}\right)$ and $\left(37.82 \mathrm{ng} \mathrm{mL}^{-1}\right)$ in untreated and treated drinking water samples, respectively. Thus, in the case of DCF, the Standard addition method was carried out which proved the validity of the proposed method. Regarding CBZ and TCS, spiked water samples were analyzed, and recovery was computed using the regression equation (Table 4).

\subsection{Statistical analysis}

A statistical comparison between the results of the proposed method and those of the reported methods [17-19] was carried out using the student's t-test and $\mathrm{F}$ test at a $95 \%$ confidence level, (Table 5). The proposed methods were found to be accurate and precise since there was no statistically significant difference between 
both the proposed and the reported methods.

\subsection{Greenness assessment}

Greening an analytical procedure as well as achieving the analytical figures of merit such as selectivity, specificity, and limit of detection have introduced a great challenge to the analyst in developing a green analytical method. Eliminating the toxicity of the analytical methods can be achieved via different strategies including reduction of the number of solvents used in sample pretreatment and extraction, replacement of hazardous solvents with greener ones and elimination of the amount of waste [26]. In the proposed method, using solid-phase extraction achieved the reduction in the amount of solvent, also using water and ethanol in the determination steps and shortening the analysis time were the essential keys that contributed to the greenness of the proposed method. Evaluation of the greenness of the developed analytical methods is highly recommended and as a result, several tools were developed such as the National Environmental Methods Index (NEMI) which is considered the oldest tool for assessing the greenness of the analytical procedure [27], Analytical Eco-scale [28] and Green analytical procedure Index (GAPI) [29], which is considered as one of the most recent tools used in the greenness assessment. For the assessment of the proposed method, Analytical eco-scale and GAPI tools were employed for their greenness assessment.

\subsection{Analytical eco-scale}

It is based on penalty points which are assigned to different factors included in the proposed method and finally subtracted from a base of 100. The score will be more than 75 for excellent green analysis, more than 50 for acceptable green analysis and less than 50 for inadequate green analysis. The reagent type and amount, the amount of energy of various electrical devices, the analytical waste treatment, and the occupational hazard are all given penalty points [28]. The proposed method was found to be an excellent green analytical method (Table 6).

\subsection{Green Analytical Procedure Index}

It is one of the most recent tools, which are used to evaluate the greenness of analytical methods since it evaluates the greenness of the whole method starting from the sample collection until the final determination. It consists of five pentagrams with three levels of color scale for each stage including green, yellow or red ranging from high, medium and low environmental impact [29]. In the proposed method, there were only 3 red regions. The first one corresponds to sample collection, it wasn't possible to do it either on-line or in- line but to overcome this point the addition of preservatives was avoided and the analysis was carried out within $24 \mathrm{~h}$ from the collection and the samples were kept at $4{ }^{\circ} \mathrm{C}$. The second red region corresponds to the extraction step since a direct analysis wasn't applicable but solid-phase extraction, a greener extraction method, which requires less amount of solvents and also benign nontoxic solvents were used. Finally, the last red one corresponds to waste treatment since there was no opportunity to carry out this step, but fortunately, the proposed method produced low amounts of waste due to short run time less than $10 \mathrm{~mL}$ (Fig. 3).

Finally, both tools, Eco scale, and GAPI were valuable tools to evaluate the greenness of the proposed method but upon comparing between them, GAPI has two advantages of being easier to apply and giving an overall view of the whole method starting from sample collection until the final findings helping the analyst to know the weakest points in the analytical method and how to overcome them. 
Table 5. Statistical comparison between the published methods and the proposed methods

\begin{tabular}{|c|c|c|c|c|c|c|}
\hline \multirow[t]{2}{*}{ Parameter } & \multicolumn{2}{|c|}{ DCF } & \multicolumn{2}{|c|}{$\mathrm{CBZ}$} & \multicolumn{2}{|c|}{ TCS } \\
\hline & $\begin{array}{c}\text { Published } \\
\text { method }\end{array}$ & $\begin{array}{l}\text { Proposed } \\
\text { method }^{\text {a }}\end{array}$ & $\begin{array}{c}\text { Published } \\
\text { method }\end{array}$ & $\begin{array}{l}\text { Proposed } \\
\text { method }^{b}\end{array}$ & $\begin{array}{c}\text { Published } \\
\text { method }\end{array}$ & $\begin{array}{l}\text { Proposed } \\
\text { method }^{\mathrm{c}}\end{array}$ \\
\hline Mean & 99.95 & 100.42 & 99.83 & 99.56 & 100.24 & 99.69 \\
\hline SD & 1.405 & 1.381 & 1.282 & 0.733 & 0.483 & 0.919 \\
\hline Variance & 1.98 & 1.90 & 1.64 & 0.54 & 0.23 & 0.84 \\
\hline $\mathbf{n}$ & 5 & 5 & 5 & 5 & 5 & 5 \\
\hline $\mathbf{t}$ & & $0.54(2.31)^{*}$ & & $0.41(2.31)^{*}$ & & $1.16(2.31)^{*}$ \\
\hline $\mathbf{F}$ & & $1.03(6.39)^{*}$ & & $3.07(6.39)$ * & & $3.60(6.39)^{*}$ \\
\hline
\end{tabular}

The theoretical values of $t$ and $F$ at $P=0.05---$

${ }^{a}$ Spectrofluorimetric determination of DCF [18] by setting the excitation and emission wavelengths at 287 and 362 $\mathrm{nm}$ respectively. slit widths were set at 5 , spectral band width was $2 \mathrm{~nm}$ and diluting solvent $(0.01 \mathrm{~N} \mathrm{HCl})$.

${ }^{\mathrm{b}}$ High performance liquid chromatography determination of CBZ [17] by using a C18, $5 \mu(250 \times 4.6 \mathrm{~mm}) \mathrm{column}$, a mobile phase of methanol: water (70: 30, v/v) at flow rate $1.5 \mathrm{~mL} \cdot \mathrm{min}^{-1}$ and UV detection at $\lambda=285 \mathrm{~nm}$ using 10 $\mu \mathrm{L}$ as an injection volume.

${ }^{\mathrm{c}}$ High performance liquid chromatography determination of TCS [19] by using a C18, $5 \mu(250 \times 4.6 \mathrm{~mm}) \mathrm{column}$, a mobile phase of methanol: water (90: 10, v/v) at flow rate $1 \mathrm{~mL} \cdot \mathrm{min}^{-1}$ and UV detection at $\lambda=280 \mathrm{~nm}$ using $20 \mu \mathrm{L}$ as an injection volume.

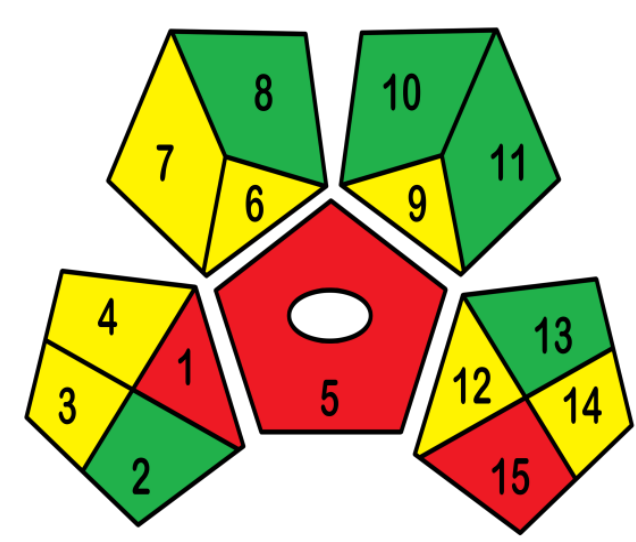

(a)

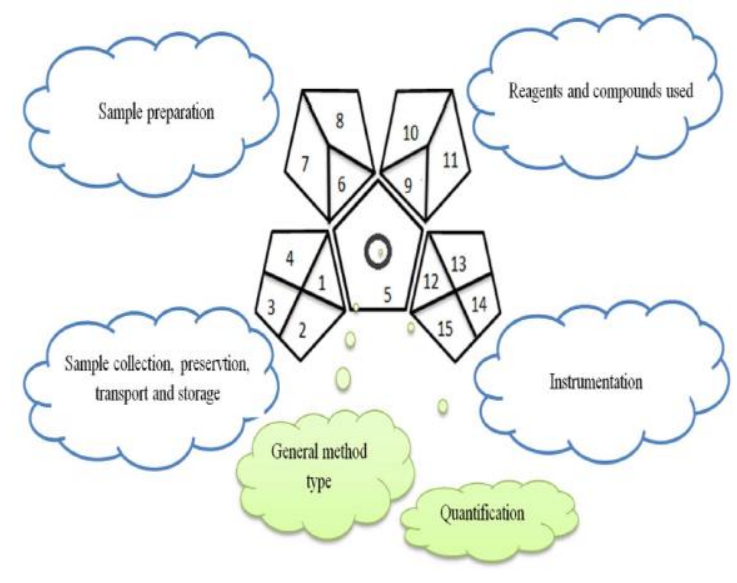

(b)

Fig. 3. GAPI for the assessment of the proposed HPLC/DAD (a)

(b) Płotka-Wasylka, J. (2018). A new tool for the evaluation of the analytical procedure: Green Analytical Procedure Index. Talanta, 181, 204-209.

Table 6. The penalty points for the proposed method using Analytical eco-scale method of assessment 


$\begin{array}{cc}\text { Reagents: } & \\ -\quad \text { Ethanol } & 8 \\ -\quad \text { Water } & 0 \\ \text { Instruments: } & 0 \\ -\quad \text { Energy and occupational hazard } & 6 \\ -\quad \text { Waste } & 14 \\ \text { Total penalty points } & 86 \\ \text { Analytical eco-scale for the proposed method } & \end{array}$

\section{Conclusion}

The global growing need to eliminate the use of toxic chemicals and lower the environmental toxic discharges compels us to develop green analytical methods for the determination of various environmental contaminants.

In this work, we developed a validated simple, green, rapid, cheap and highly sensitive HPLC/ DAD method for the determination of various emerging water contaminants, and it was successfully applied for the analysis of two different water samples with no need for prior separation. This was achieved by using ethanol as an organic modifier and short run time which contributed to the simplicity and greenness of the method.

\section{Acknowledgments}

This work is part of the project entitled "Environmental pollution in Egypt: development of sensitive analytical methods for determination and elimination of pollutants" funded by the Department of Postgraduate studies and research, Ain Shams University, Cairo, Egypt.

List of abbreviations: HPLC: High-performance liquid chromatography; DAD: Diode array detector; RP: reversed-phase; ICH: International conference on harmonization; DCF: Diclofenac; CBZ: Carbamazepine; TCS: Triclosan; SPE: Solid-phase extraction; HETP: Height equivalent to theoretical plate; RSD: Relative standard deviation; LOQ: Limit of quantitation; LOD:
Limit of detection; NEMI: National Environmental Methods Index; GAPI: Green analytical procedure Index.

\section{REFERENCES}

1. Daughton CG. Environmental stewardship and drugs as pollutants. Lancet. 2002; 360(9339): 1035-1036. $\quad$ https://doi.org/10.1016/S0140$\underline{6736(02) 11176-7}$

2. Richardson SD, Kimura SY. Emerging environmental contaminants: Challenges facing the next generation and potential engineering solutions. Environ Technol Inno. 2017; 8: 40-56. https://doi.org/10.1016/j.eti.2017.04.002

3. Valcárcel Y, Alonso SG, Rodríguez-Gil JL, Maroto RR, Gil A, Catalá M. Analysis of the presence of cardiovascular and analgesic/antiinflammatory/antipyretic pharmaceuticals in the river- and drinking-water of the Madrid Region in Spain. Chemosphere. 2011; 82(7): 1062-1071. https://doi.org/10.1016/j.chemosphere.2010.10.041

4. Rasheed T, Bilal M, Nabeel F, Adeel M, Iqbal HMN. Environmentally-related contaminants of high concern: Potential sources and analytical modalities for detection, quantification, and treatment. Environ. Int. 2019; 122: 52-66. https://doi.org/10.1016/j.envint.2018.11.038

5. Comtois-Marotte S, Chappuis T, Vo Duy S, et al. Analysis of emerging contaminants in water and solid samples using high-resolution mass spectrometry with a Q Exactive orbital ion trap and estrogenic activity with YES-assay. Chemosphere. 2017; 166: 400-411. https://doi.org/10.1016/j.chemosphere.2016.09.077 
6. Schwaiger J, Ferling H, Mallow U, Wintermayr H, Negele RD. Toxic effects of the non-steroidal antiinflammatory drug diclofenac. Part I: Histopathological alterations and bioaccumulation in rainbow trout. Aquat. Toxicol. 2004; 68(2): 141-150.

https://doi.org/10.1016/j.aquatox.2004.03.014

7. Orvos DR, Versteeg DJ, Inauen J, Capdevielle M, Rothenstein A, Cunningham V. Aquatic toxicity of triclosan. Environ. Toxicol. Chem. 2002; 21(7): 1338-1349.

https://doi.org/10.1002/etc.5620210703

8. Vernouillet G, Eullaffroy P, Lajeunesse A, Blaise C, Gagné F, Juneau P. Toxic effects and bioaccumulation of carbamazepine evaluated by biomarkers measured in organisms of different trophic levels. Chemosphere. 2010; 80(9): 10621068.

https://doi.org/10.1016/j.chemosphere.2010.05.010

9. van den Brandhof EJ, Montforts M. Fish embryotoxicity of carbamazepine, diclofenac, and metoprolol. Ecotoxicol. Environ. Saf. 2010; 73(8): 1862-1866.

https://doi.org/10.1016/j.ecoenv.2010.08.031

10. Kuster M, López de Alda MJ, Hernando MD, Petrovic M, Martín-Alonso J, Barceló D. Analysis and occurrence of pharmaceuticals, estrogens, progestogens and polar pesticides in sewage treatment plant effluents, river water and drinking water in the Llobregat river basin (Barcelona, Spain). J. of Hydrol. 2008; 358(1-2): 112-123. https://doi.org/10.1016/j.jhydrol.2008.05.030

11. Vieno NM, Tuhkanen T, Kronberg L. Analysis of neutral and basic pharmaceuticals in sewage treatment plants and recipient rivers using solidphase extraction and liquid chromatographytandem mass spectrometry detection. J. Chromatogr. A. 2006; 1134(1-2): 101-111. https://doi.org/10.1016/j.chroma.2006.08.077

12. Trenholm RA, Vanderford BJ, Holiday JC, Rexing DJ, Snyder SA. Broad range analysis of endocrine disruptors and pharmaceuticals using gas chromatography and liquid chromatographytandem mass spectrometry. Chemosphere. 2006; 65(11):

1990-1998. https://doi.org/10.1016/j.chemosphere.2006.07.004

13. Mohan S, Balakrishnan P. Triclosan in Treated Wastewater from a City Wastewater Treatment Plant and its Environmental Risk Assessment. Water Air Soil Pollut. 2019; 230(3): 1-13. https://doi.org/10.1007/s11270-019-4098-9

14. Schmidt S, Hoffmann H, Garbe LA, Schneider RJ. Liquid chromatography-tandem mass spectrometry detection of diclofenac and related compounds in water samples. J. Chromatogr. A. 2018; 1538: 112-116.

https://doi.org/10.1016/j.chroma.2018.01.037

15. Tran NH, Gin KYH. Occurrence and removal of pharmaceuticals, hormones, personal care products, and endocrine disrupters in a full-scale water reclamation plant. Sci. Total Environ. 2017; 599-600: 1503-1516. https://doi.org/10.1016/j.scitotenv.2017.05.097

16. Archer E, Petrie B, Kasprzyk-Hordern B, Wolfaardt GM. The fate of pharmaceuticals and personal care products (PPCPs), endocrinedisrupting contaminants (EDCs), metabolites and illicit drugs in a WWTW and environmental waters. Chemosphere. 2017; 174: 437-446. https://doi.org/10.1016/j.chemosphere.2017.01.101

17. Sheikh REL, Gouda AA, Hassan WS. Development and Validation of a Rapid stabilityindicating HPLC Method for Determination of Carbamazepine in Pure and Dosage Forms. Chem. Sci. Trans. 2016; 5(4): 1026-1034. https://doi.org/10.7598/cst2016.1268

18. Damiani P, Bearzotti M, Cabezón MA. Spectrofluorometric determination of diclofenac in tablets and ointments. J. Pharmaceut. Biomed. 1999; 20: 587-590. https://doi.org/10.1016/S07317085(99)00052-7

19. Baranowska I, Magiera S, Bortniczuk K. Reversephase HPLC method for the simultaneous analysis of triclosan and triclocarban in surface waters. Water Sci. Tech.-W. Supply. 2010; 10(2): 173-180. https://doi.org/10.2166/ws.2010.242

20. Hemdan A, Magdy R, Farouk M. Response surface design as a powerful tool for the development of environmentally benign HPLC 
methods for the determination of two antihypertensive combinations: Greenness assessment by two green analytical chemistry evaluation tools. J. Sep. Sci. 2018; 41(16): 32133223. https://doi.org/10.1002/jssc.201800317

21. Sheldon RA. Fundamentals of green chemistry: Efficiency in reaction design. Chem. Soc. Rev. 2012; 41(4): 1437-1451. https://doi.org/10.1039/C1CS15219J

22. Shen Y, Chen B, Van Beek TA. Alternative solvents can make preparative liquid chromatography greener. Green Chem. 2015; 17(7): 4073-4081. https://doi.org/10.1039/C5GC00887E

23. Tomaszewski M, Namieśnik J. Greener organic solvents in analytical chemistry. Curr. Opin. Green and Sustain. Chem. 2017; 5: 1-4. https://doi.org/10.1016/j.cogsc.2017.03.002

24. Sadek PC. The HPLC Solvent Guide. Wiley: New York, 1996.

25. Guideline IHT. Validation of analytical procedures: text and methodology Q2 (R1). In International Conference on Harmonization, In International Conference on Harmonization: Geneva, Switzerland, 2005; 11-12.

26. Armenta S, Garrigues S, de la Guardia M. Green analytical chemistry. TRAC-Trend Anal. Chem. 2009; 27(6): 63-96. https://doi.org/10.1016/j.trac.2008.05.003

27. Keith LH, Gron LU, Young JL. Green Analytical Methodologies. Chem. Rev. 2007; 107(6): 26952708. https://doi.org/10.1021/cr068359e

28. Gałuszka A, Migaszewski ZM, Konieczka P, Namieśnik J. Analytical Eco-Scale for assessing the greenness of analytical procedures. TRACTrend Anal. Chem. 2012; 37(July): 61-72. https://doi.org/10.1016/j.trac.2012.03.013

29. Płotka-Wasylka J. A new tool for the evaluation of the analytical procedure: Green Analytical Procedure Index. Talanta. 2018; 181(September 2017): 204-209. https://doi.org/10.1016/j.talanta.2018.01.013. 